\title{
Research Square \\ Distributed MEMS Sensors using Plasmonic Antenna Array Embedded Sagnac Interferometer
}

\section{Anita Garhwal}

Amity University Rajasthan: Amity University - Jaipur Campus

\section{Arumona Edward Arumona}

Ton Duc Thang University

\section{Phichai Youplao}

Ton Duc Thang University

\section{Kanad Ray}

Amity University Rajasthan: Amity University - Jaipur Campus

Preecha Yupapin ( $\nabla$ preecha.yupapin@tdtu.edu.vn )

Ton Duc Thang University https://orcid.org/0000-0002-5257-4351

\section{Research Article}

Keywords: Integrated MEMS resonator, Sagnac interferometer, Microring resonator, Electron cloud sensors

Posted Date: May 19th, 2021

DOI: https://doi.org/10.21203/rs.3.rs-478714/v1

License: (c) (1) This work is licensed under a Creative Commons Attribution 4.0 International License. Read Full License 


\title{
Distributed MEMS Sensors using Plasmonic Antenna Array Embedded Sagnac Interferometer
}

\author{
Anita Garhwal ${ }^{1}$, Arumona Edward Arumona ${ }^{2,3,4}$, Phichai Youplao $^{2 *}, 3$, Kanad Ray ${ }^{5}$, Preecha \\ Yupapin $^{2 * 3}$
}

${ }^{1}$ Amity School of Engineering and Technology, Amity University Rajasthan, Jaipur, India.; ${ }^{2}$ Computational Optics Research Group, Advanced Institute of Materials Science, Ton Duc Thang University, Ho Chi Minh City, Vietnam; ${ }^{3}$ Faculty of Applied Sciences, Ton Duc Thang University, Ho Chi Minh City, Vietnam; ${ }^{4}$ Division of Computational Physics, Institute for Computational Science, Ton Duc Thang University, Ho Chi Minh City, Vietnam; ${ }^{5}$ Amity School of Applied Sciences, Amity University Rajasthan, Jaipur, India; *Correspondence: preecha.yupapin@tdtu.edu.vn;

\begin{abstract}
A micro Sagnac interferometer is proposed for electron cloud distributed sensors formed by an integrated (micro-electro-mechanical systems) MEMS resonator structure. The Sagnac interferometer consists of four microring probes integrated into a Sagnac loop. Each of the microring probes is embedded with the silver bars to form the plasmonic wave oscillation. The polarized light of $1.50 \mu \mathrm{m}$ wavelength is input into the interferometer, which is polarized randomly into upstream and downstream directions. The polarization outputs can be controlled by the space-time input at the Sagnac port. Electrons are trapped and oscillated by the whispering gallery modes (WGMs), where the plasmonic antennas are established and applied for wireless fidelity (WiFi) and light fidelity (LiFi) sensing probes, respectively. Four antenna gains are $2.59 \mathrm{~dB}, 0.93 \mathrm{~dB}, 1.75 \mathrm{~dB}$, and $1.16 \mathrm{~dB}$, respectively. In manipulation, the sensing probe electron densities are changed by input source power variation. When the electron cloud is excited by the microscopic medium, where the change in electron density is obtained and reflected to the required parameters. Such a system is a novel device that can be applied for brain-device interfering with the dual-mode sensing probes. The obtained WGM sensors are $1.35 \mu \mathrm{m}^{-2}, 0.90 \mu \mathrm{m}^{-2}, 0.97 \mu \mathrm{m}^{-2}$ and, $0.81 \mu \mathrm{m}^{-2}$, respectively. The WGMs behave as a four-point probe for the electron cloud distributed sensors, where the electron cloud sensitivities of $2.31 \mathrm{prads}^{-1} \mathrm{~mm}^{3}$ (electrons) ${ }^{-1}, 2.27 \mathrm{prads}^{-1} \mathrm{~mm}^{3}$ (electrons) ${ }^{-1}, 2.22 \mathrm{prads}^{-}$ ${ }^{1} \mathrm{~mm}^{3}$ (electrons $)^{-1}, 2.38$ prads $^{-1} \mathrm{~mm}^{3}$ (electrons $)^{-1}$ are obtained, respectively.
\end{abstract}

Keywords: Integrated MEMS resonator; Sagnac interferometer; Microring resonator; Electron cloud sensors.

\section{Introduction}

Sagnac interferometer is one of the interferometer types, which can be applied in many applications [1-3]. The principle is that the Sagnac interferometer setup usually involves a ring configuration where the light beam splits into two beams. The two beams travel around the ring path but in opposite directions, and the two beams undergo interference on returning to the entry point of the Sagnac interferometer. There are different types of Sagnac interferometers that have been designed, developed, and employed for sensing applications [4-8]. The micro-scale system known as micro-electro-mechanical system (MEMS) technology is used to develop resonators for various applications [9-12], where the resonators such as panda ring, micro ring, and MZI have been applied. Recently, microring resonators have been widely used in both theoretical and experimental works [13-16], where the realistic applications have been confirmed. Various works of MEMS using microring resonators have also been found [17-20]. The review of the micromachined resonator is presented by Reza et al. [17], where the basic model with the electric circuit, resonant modes, and fabrication process are explained. Another MEMS application is the accelerometer-based optical modulator using MZI was presented [9], which was fabricated on silicon-oninsulator, where one branch of MZI is fixed, and another branch uses a floating waveguide. The waveguide-based MZI and gyroscope were already designed and presented [21-22]. Other forms of MEMS and interferometers have been proposed, where Arumona et al. [23] have proposed the use of microring resonator embedded FarbyPerot interferometer, which can be useful for sensing applications, especially for nano/micro-scale measurement regimes. The Fabry-Perot structure is different from the Sagnac one. Both are designed and used microring structure and space-time control, where Fabry-Perot one has applications in quantum spectroscopy, quantum sensor, and microscopy regime. More details of interferometers and microring resonators can be found in the given references [24-27]. A microring embedded Sagnac interferometer is proposed for an integrated MEMS resonator structure, which can be applied for nano/micro-scale sensors, especially for micromachine applications. The integrated MEMS resonator provides compact, lightweight, and low-cost devices. The use of the integrated MEMS resonator structure has been proposed in various applications [28-31]. The integrated photonic circuits 
have also been applied in quantum communication and molecular sensing [32]. In this work, the proposed planar waveguide Sagnac interferometer dimensions are in the form of the integrated MEMS resonators. The main emphasis of the current work is to design an integrated Sagnac interferometer for electron cloud sensors. Four microrings are embedded with the silver bars at the center of the microrings, from which the electro-optic sensing probes can be formed. An isolator is used at the input to control the reflected signal. Four whispering gallery modes (WGMs) are formed by the nonlinear effect coupled by the two side rings, from which the electron cloud is trapped and oscillated by the plasmonic waves. These WGMs act as four-probe sensors. The polarized laser is fed into the Sagnac interferometer, from which the output is split by a beamsplitter. The OptiFDTD software is employed for the design and simulation while the Matlab program employs the extracted parameters from the simulation results to plot the graphs and obtain other results. In this current work, the Sagnac interferometer structure waveguide for brain interfacing device sensors is proposed. The polarized laser is applied to form the quantum distributed sensors. The quantum sensors and human quantum consciousness investigation can be applied using the electron cloud distribution within the brain-device interfacing system.

\section{Theoretical Background}

The Sagnac interferometer circuit is shown in Figure 1. The input signal is the polarized laser [23, 33], which is given by an equation (1).

$$
E_{\text {in }}=E_{0} \cdot \exp \left(-i k_{z} z\right)
$$

where $k_{z}=\frac{2 \pi}{\lambda}$ is the wave number of the wave vector in the z-axis, $\lambda$ is the wavelength, and $E_{0}$ is the initial amplitude of the field, and $\mathrm{z}$ is the propagation distance in the $\mathrm{z}$-axis.

The propagation of light pulse within the nonlinear material and in refractive index $(n)$ is given as [23, 33].

$$
n=n_{0}+n_{2} I=n_{0}+\frac{n_{2}}{A_{\text {eff }}} P
$$

Where $n_{0}, n_{2}, I$ and $P, A_{\text {eff }}$ are the linear and nonlinear refractive indices, optical intensity and optical power, effective core area, respectively. The light pulse follows the two paths for propagation which are clockwise and anticlockwise. After traveling through two paths, a phase shift is introduced in the output pulse.
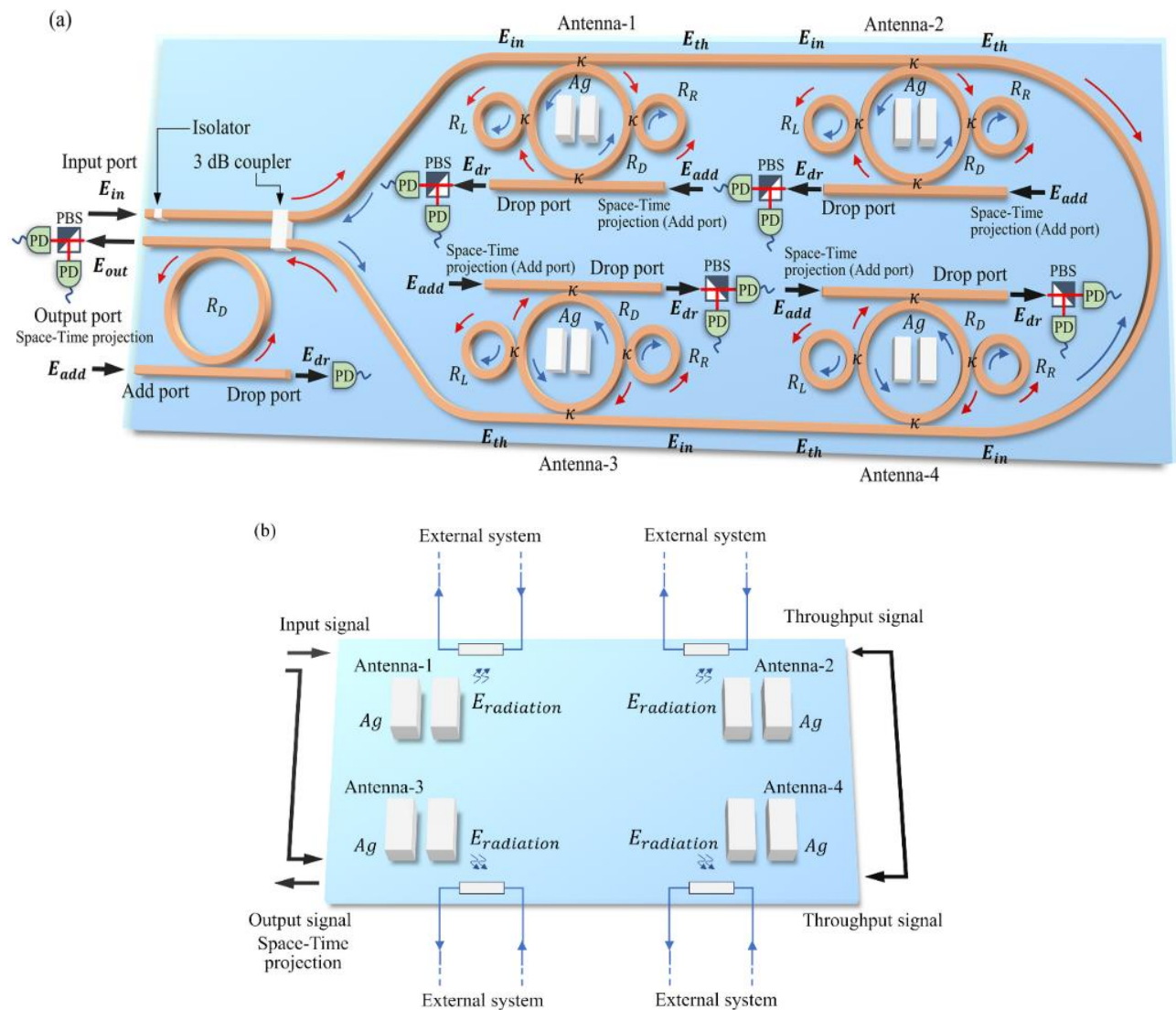

Figure 1. The device fabricated/ simulated structure of proposed work, where (a) micro-electron cloud sensors network system; Ein, Eth, Edr, E add are electric fields at input, throughput, drop and add ports, respectively. $\kappa$ is coupling constants. PBS: Polarizing beamsplitter, PD: photodetector. The polarized electron cloud components can be obtained, (b) an equivalent sensing probe circuit. The micro rings are embedded with silver (Ag) nano bars. The optical isolator is applied to project the feedback to the laser source. 
The electron behavior of the silver bars at the four center microrings is described by the Drude model [21], which is given as:

$$
\epsilon(\omega)=1-\frac{n_{e} e^{2}}{\epsilon_{0} m \omega^{2}}
$$

where $n_{e}$ is the electron density, $m$ is the mass, $\omega$ is the angular frequency, $\epsilon_{0}$ is the relative permittivity, $e$ is the electron charge. The plasma frequency $\left(\omega_{p}\right)$ at the resonance is obtained from the angular frequency, which is given by the equation (4) [21].

from equation (4), $n_{e}=\frac{\omega_{p \epsilon_{0} m}^{2}}{e^{2}}$.

$$
\omega_{p}=\left[\frac{n_{e} e^{2}}{\epsilon_{0} m}\right]^{-1 / 2}
$$

The space time modulation signal is applied at the add port $\left(E_{a d d}\right)$ of the microring, the polarization component can be calculated and used for quantum interpretation. The space time signal is given by an equation (5) [34].

$$
E_{\text {add }}=A e^{ \pm i \omega t}
$$

where A, $\omega$, and t are amplitude, angular frequency, and time. A space time modulation signal is applied to achieve polarized output. The \pm shows both axes of time.

The excited electrons are trapped inside the four microring resonators, where the four of WGMs' formations are taken place. The output at throughput $\left(E_{t h}\right)$ and drop ports $\left(E_{d r}\right)$ are given by $[21,34]$.

$$
\begin{aligned}
& E_{t h}=m 2 E_{i n}+m 3 E_{a d d} \\
& E_{d r}=m 5 E_{a d d}+m 6 E_{\text {in }}
\end{aligned}
$$

where $m 2, m 3, m 5$, and $m 6$ are constants. The system outputs are normalized intensities, which are given as:

$$
\begin{aligned}
& \frac{I_{t h}}{I_{\text {in }}}=\left[\frac{E_{t h}}{E_{\text {in }}}\right]^{2} \\
& \frac{I_{d r}}{I_{\text {in }}}=\left[\frac{E_{d r}}{E_{\text {in }}}\right]^{2}
\end{aligned}
$$

where $I_{t h}, I_{i n}$, and $I_{d r}$ are the throughput, input and drop port intensities, respectively. The phase shift is given in equation (10) [35].

$$
\phi=\pi-\frac{\beta L}{2}-\arctan \left(\frac{\kappa_{2} \kappa_{4} \gamma_{1} \gamma_{3} \alpha^{4} \sin \beta L}{1-\kappa_{2} \kappa_{4} \gamma_{1} \gamma_{3} \alpha^{4} \cos \beta L}\right)
$$

where $\kappa_{2}, \kappa_{4}$ are coupling coefficients, $\gamma$ is insertion loss, $\alpha$ is attenuation coefficient, $\beta$ is propagation constant and $L=2 \pi r$, where $r$ is the radius of the center microring. The integrated system for the microring distributed electron cloud sensor network is designed and simulated in OptiFDTD. The four microring circuits inside the Sagnac form the WGM. The designed system is explained using equations (1) to (10).

\section{Methods}

Figure 1 shows the designed structure of the microring distributed electron cloud sensors system. The input signal is applied at the input port. The input light is a polarized laser. The materials of Sagnac and microring are silica and $\mathrm{Si}$, respectively. The light travels in the upper and lower branches of the Sagnac loop. The Sagnac loop is embedded with four microring resonator circuits. The radius of center microring $\left(\mathrm{R}_{\mathrm{D}}\right)$ is bigger than the side ring radius $\left(\mathrm{R}_{\mathrm{L}}, \mathrm{R}_{\mathrm{R}}\right)$. The design parameters of the proposed system are shown in Table 1 . The applied microring circuit ports depend on the light flow direction in the Sagnac loop, which is the two-way propagation, where the Sagnac closed loop is the required result. The system is designed and simulated in OptiFDTD for 20,000 time-steps. The data is extracted from OptiFDTD, and graphs are plotted using MATLAB software, where Figures 2-7 show the results of the designed system. The working of the designed system is as follows. First, the input signal of wavelength $1.50 \mu \mathrm{m}$ is applied at the input port, which is a polarized laser as shown in an equation (1). Half-light energy propagates into the upper branch (upstream), and the other half into the lower branch (downstream) directions, respectively. The signal flow of the upper branch is in the clockwise direction. The lower branch is the anticlockwise direction, which is shown in Figure 1 where four microrings are integrated with the Sagnac loop. The two rings are with the upper branch and the other two with the lower branch. The micro rings are embedded with silver nano bars. Light propagates into the input port of microring-1(antenna-1), from the throughput port of antenna-1 enters into the input port of microring-2(antenna-2). It is the same operation with antenna-3 and 4. Light from the antenna- 2 and 4 throughput ports enter the throughput ports of 4 and 2, which become the input of the closed-loop operation. Similarly, from the throughput signals of antenna- 4 enter the input port of antenna-3 and from the throughput of antenna-2 to antenna- 1 . Both paths of propagated lights return at the $3 \mathrm{~dB}$ coupler. The optical isolator is applied at the input port to prevent the reflection of the backlight. The light goes into outer microring at the output port. The propagation of the light pulse in the nonlinear material is given by equation (2). The real-time experiment of the Sagnac interferometer consists of a beam-splitter. Here, the proposed system is manipulated using space-time modulation at the add port of the microrings. The Sagnac output enters into the microring, which is polarized light. The light propagates inside the microring circuits, from which the phase shift between the polarization components is obtained by the space-time projection control. The Kerr effect is a 
nonlinear effect induced by the system, and with suitable parameters, as shown in Table 1, where the WGMs are formed. The WGM is the trapping of light at the center microring. These WGMs form the antennas inside the Sagnac which consist of the trapped electrons resulting from the illumination of the silver nano-bars by light at the center microring. Figure 2 shows the graphical results of the simulated structure.
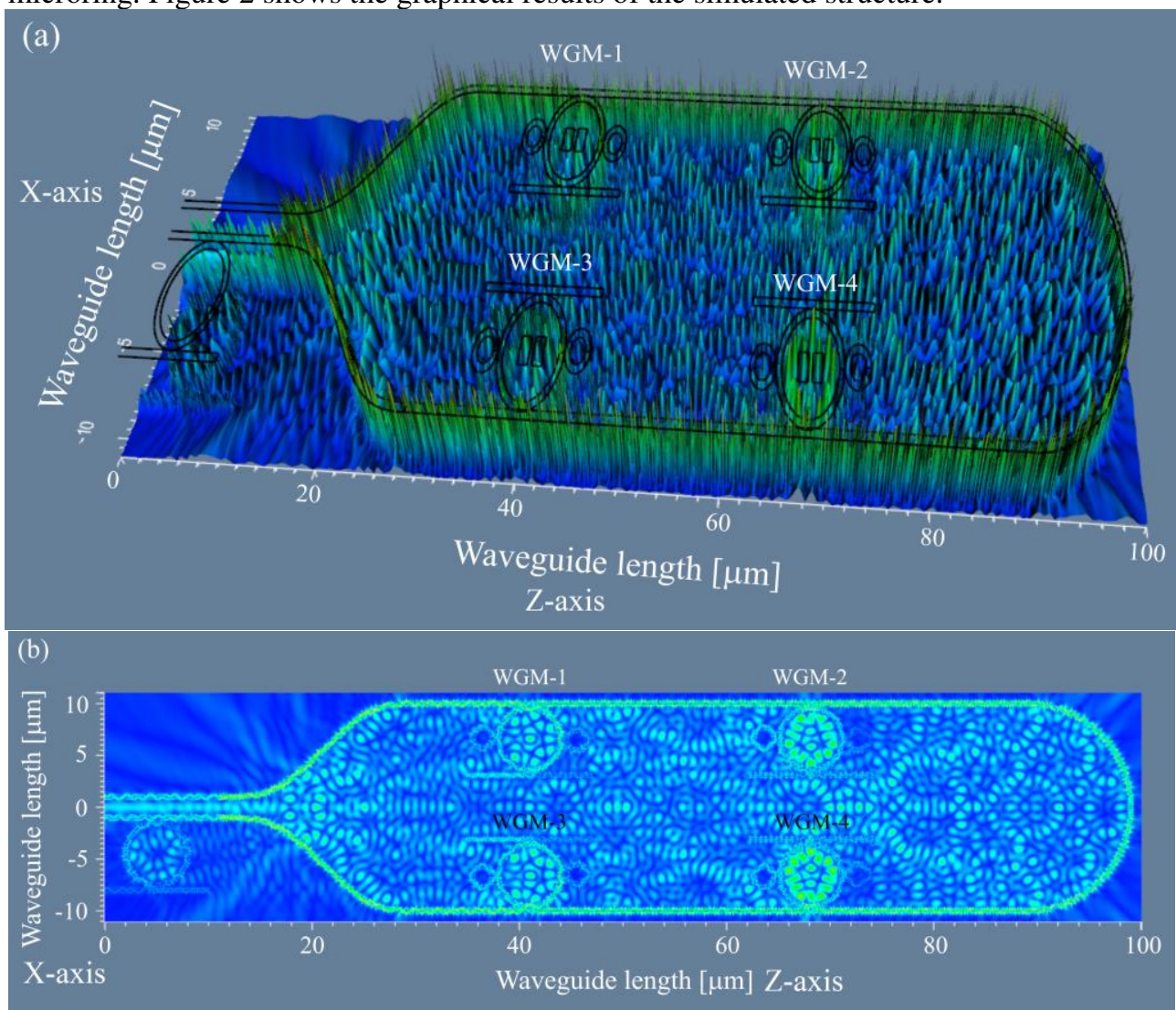

Figure 2. The Optiwave graphical results, where (a) WGMs formation; (b) plasmons propagating in the system. Input source is a polarized laser with of wavelength $1.50 \mu \mathrm{m}$. The used parameters of simulation are given in Table 1 , where $\mathrm{z}$ is the propagation axis.

Table 1. The parameters used in simulation parameters.

\begin{tabular}{|c|c|}
\hline Parameters & Values \\
\hline Input power $(P)$ & $10-15 \mathrm{~mW}$ \\
\hline Input wavelength $(\lambda)$ & $1.50 \mu \mathrm{m}$ \\
\hline Center ring radius $\left(R_{D}\right)$ & $2.0 \mu m$ \\
\hline Side rings radius $\left(R_{L}, R_{R}\right)$ & $0.80 \mu \mathrm{m}$ \\
\hline Silver refractive index $\left(n_{A g}\right)[36]$ & 0.14 \\
\hline Coupling coefficient $(\kappa)[34]$ & 0.50 \\
\hline Insertion loss $(\gamma)$ & $0.50 \mathrm{~dB}$ \\
\hline Structure dimensions $(L x W)$ & $100 \times 20 \mu m^{2}$ \\
\hline Silver bar length $(l)$ & $1.25 \mu \mathrm{m}$ \\
\hline Silver bar width $(w)$ & $2.0 \mu \mathrm{m}$ \\
\hline Silica refractive index $\left(n_{\text {sio }_{2}}\right)$ & 1.45 \\
\hline Silica nonlinear refractive index $\left(n_{2}\right)$ & $2.7 \times 10^{-16} \mathrm{~m}^{2} W^{-1}$ \\
\hline Si- refractive index $\left(n_{s i}\right)$ & 3.42 \\
\hline Fiber loss & $0.1 \mathrm{dBkm}^{-1}$ \\
\hline Core effective area $\left(A_{\text {eff }}\right)$ & $0.25 \mu m^{2}$ \\
\hline Free space permittivity $\left(\varepsilon_{0}\right)$ & $8.85 \times 10^{-12} \mathrm{Fm}^{-1}$ \\
\hline Electron mass $(\boldsymbol{m})$ & $9.11 \times 10^{-31} \mathrm{~kg}$ \\
\hline Electron charge $(q)$ & $1.60 \times 10^{-19}$ Coulomb \\
\hline Waveguide loss $(\alpha)[34]$ & $0.50 \mathrm{dBmm}^{-1}$ \\
\hline
\end{tabular}




\section{Simulation Results}

Figure 2(a) shows the formation of the four WGMs at the center microrings. Figure 2(b) shows the plasmons that propagate through the system with intense electromagnetic field. Figure 3(a) shows the frequency and input intensity plot of the four WGMs. The peak frequencies of WGM-1 to WGM-4 are 208.43THz, 198.18THz, 206.72THz, and 196.47THz, respectively while Figure 3(b) shows the wavelength and input intensity plots of the four WGMs. The antenna profiles are plotted in Figures (4-6). Figure 4 shows the antenna gain plot. Antenna gain is plotted by varying the input power from $10 \mathrm{~mW}$ to $15 \mathrm{~mW}$. A linear trend of gain is achieved with input power. The gain of antennas 1 to anetnna4 are $2.59 \mathrm{~dB}, 0.93 \mathrm{~dB}, 1.75 \mathrm{~dB}$, and $1.16 \mathrm{~dB}$, respectively. Figure 5 shows the antennas' directivities. Equation (5) gives the space-time applied at the add port and equations (6 and 7) give the microring output at throughput and drop ports. The output at the throughput and drop ports are normalized using equations ( 8 and 9). Figure 6(a-b) is the plot of the normalized electron density of antennas 1 to 4 in the frequency domain and wavelength domain. The frequency domain is employed for the WiFi (wireless fidelity) band while the wavelength domain is employed for $\mathrm{LiFi}$ (light fidelity) band. Antennas-1 to 4 are recognized for both $\mathrm{WiFi}$ and LiFi transmission. Gain and directivity are calculated using the standard formula [21, 37].
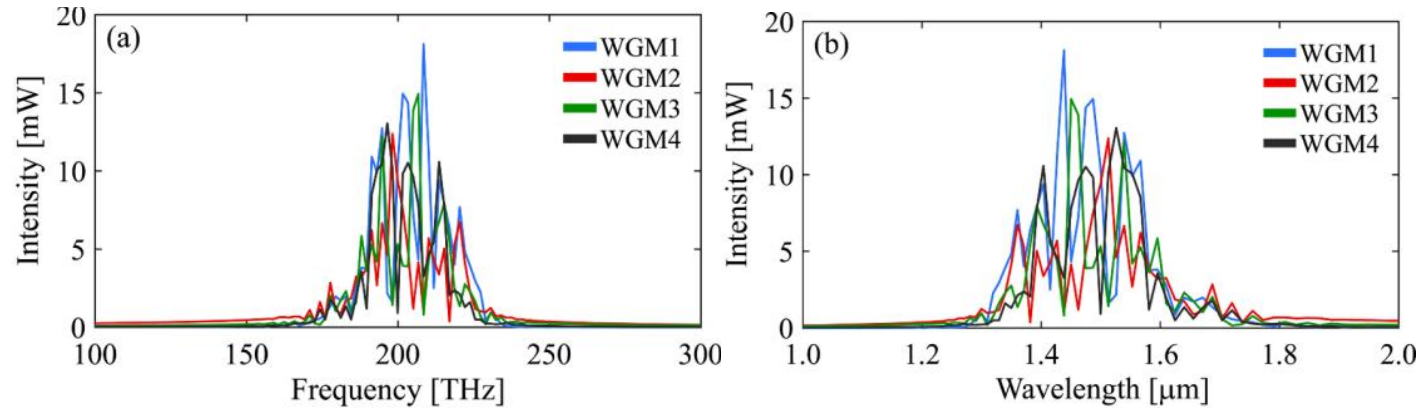

Figure 3. The plot of the input intensities and (a) frequency and (b) wavelength for all WGMs. The peak frequencies of WGM-1, WGM-2, WGM-3, and WGM-4 are 208.43THz, 198.18THz, 206.72 and, $196.47 \mathrm{THz}$, respectively.

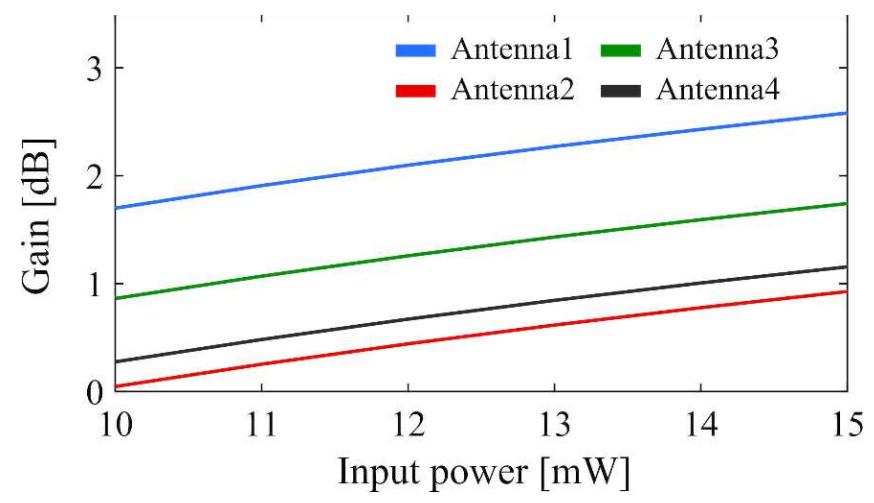

Figure 4. The plot of antennas' gains and input power. The input power varied from $10-15 \mathrm{~mW}$. The obtained gains are $2.59 \mathrm{~dB}$, $0.93 \mathrm{~dB}, 1.75 \mathrm{~dB}$, and $1.16 \mathrm{~dB}$ for antenna-1, antenna-2, antenna- 3 , and antenna- 4 , respectively.
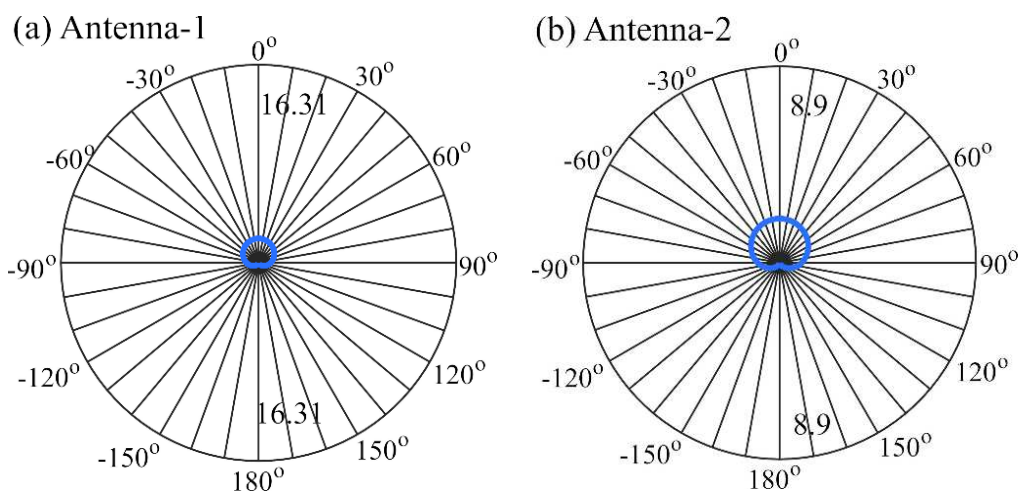
(c) Antenna-3

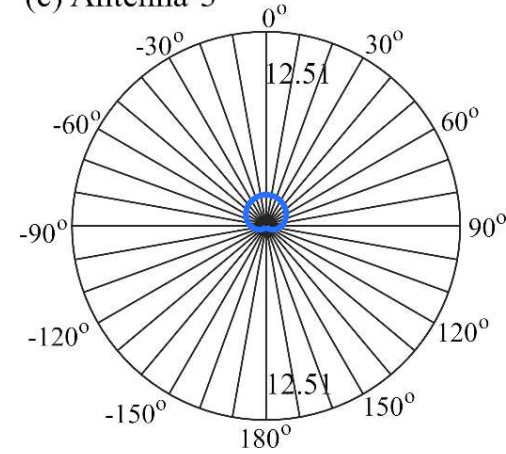

(d) Antenna-4

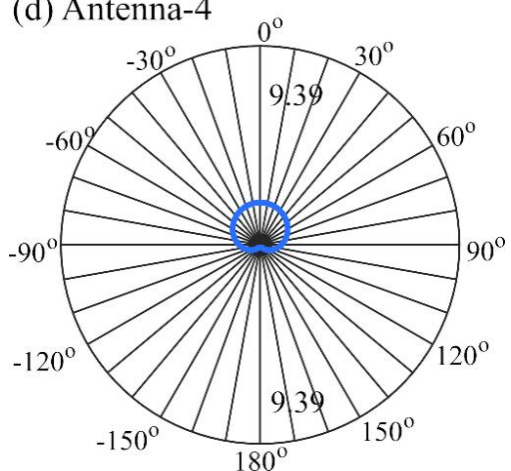

Figure 5. The plot of directivities of antennas, where the obtained directivities are 16.31, 8.9, 12.51, and 9.39 for antenna-1, antenna-2, antenna-3, and antenna-4, respectively.
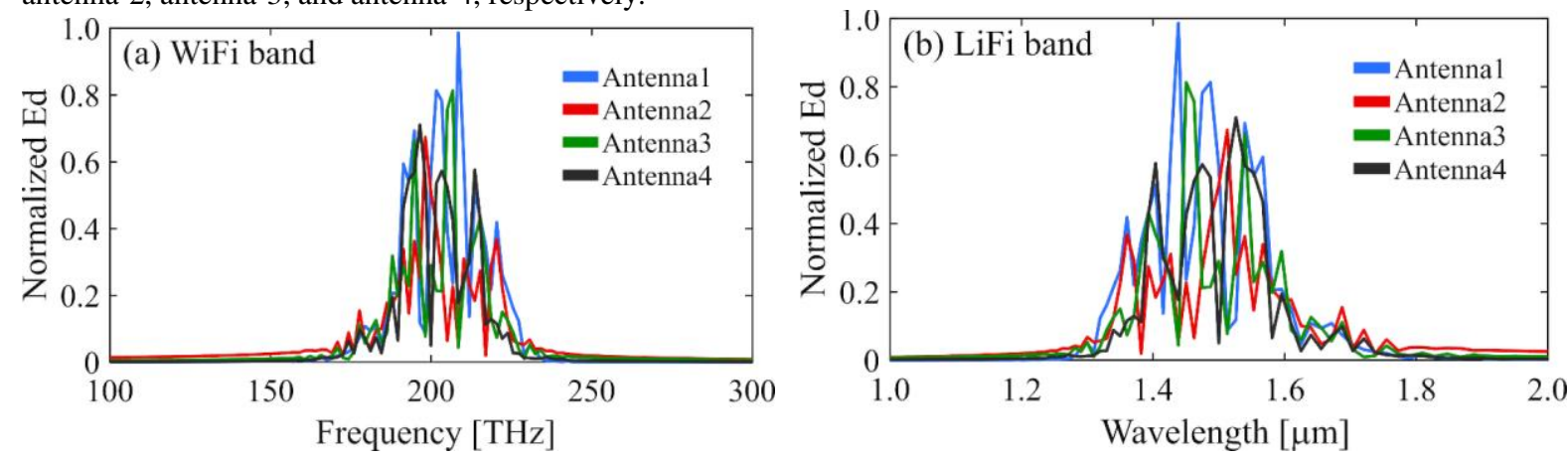

Figure 6. The plot of antenna profiles, where (a)WiFi band frequencies of antenna 1 to 4 are 208.43THz, 198.18THz, 206.72THz, and 196.47THz, respectively, (b)LiFi band wavelengths of antenna 1 to 4 are $1.43 \mu \mathrm{m}, 1.51 \mu \mathrm{m}, 1.45 \mu \mathrm{m}, 1.52 \mu \mathrm{m}$, respectively.

Figure 7 shows the output intensity plot of the four WGMs. The input power is varied from $10 \mathrm{~mW}-15 \mathrm{~mW}$.A linear trend of the output intensity of the four WGMs is achieved with input power. The sensitivities of $1.35 \mu \mathrm{m}^{-}$ ${ }^{2}, 0.90 \mu \mathrm{m}^{-2}, 0.97 \mu \mathrm{m}^{-2}$ and, $0.81 \mu \mathrm{m}^{-2}$ are obtained, respectively. The plasma frequency and electron density are related as given in equation (4). In the silver nano-bars, the electron density oscillations depend on the plasma frequency. Figure 8 shows the plot of the plasma frequency and electron density. The sensitivities of 2.31 prads $^{-}$ ${ }^{1} \mathrm{~mm}^{3}$ (electrons) $)^{-1}, 2.27$ prads $^{-1} \mathrm{~mm}^{3}$ (electrons) ${ }^{-1}, 2.22$ prads $^{-1} \mathrm{~mm}^{3}$ (electrons) ${ }^{-1}, 2.38$ prads $^{-1} \mathrm{~mm}^{3}$ (electrons) ${ }^{-1}$ are respectively obtained, where p is Pico $\left(10^{-12}\right)$. Figure 9 (a) is the plot of the change in electron density (normalized electron density) and input power. The input power is varied where the sensitivities of $0.06 \mathrm{~mW}^{-1}, 0.04 \mathrm{~mW}^{-1}$, $0.05 \mathrm{~mW}^{-1}, 0.03 \mathrm{~mW}^{-1}$ are obtained respectively for the four probes while Figure $9(\mathrm{~b})$ is the plot of the change in electron density (normalized electron density) and the phase shift (as given in equation (10)) where the sensitivities of $0.005\left({ }^{\circ}\right)^{-1}, 0.003\left({ }^{\circ}\right)^{-1}, 0.004\left({ }^{\circ}\right)^{-1}, 0.002\left(^{\circ}\right)^{-1}$ are obtained respectively for the four probes. These four WGMs behave as a four-point probe for the electron cloud sensors network. The proposed system has applications in spectroscopy and quantum sensing.

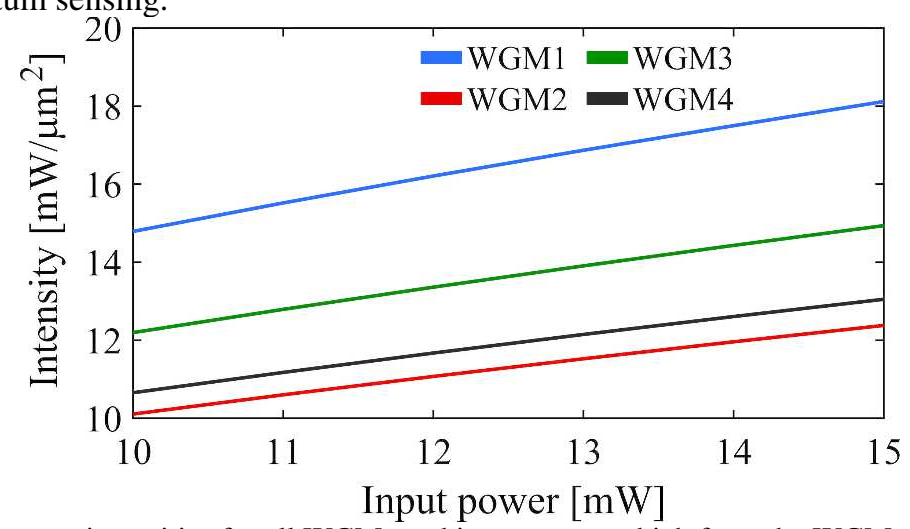

Figure 7. The plot of the output intensities for all WGMs and input power which form the WGM sensors. The input power is varied from $10-15 \mathrm{~mW}$. The sensitivities of $1.35 \mu \mathrm{m}^{-2}, 0.90 \mu \mathrm{m}^{-2}, 0.97 \mu \mathrm{m}^{-2}$, and $0.81 \mu \mathrm{m}^{-2}$, are obtained, respectively. 


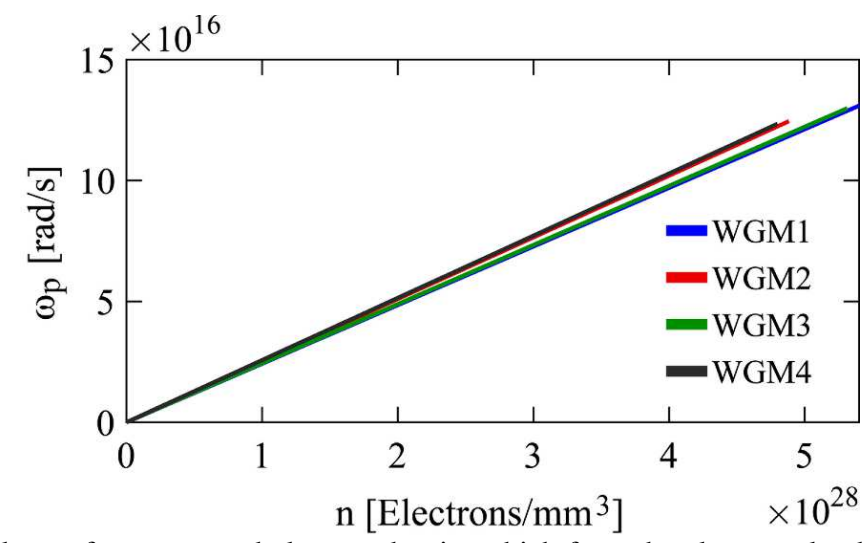

Figure 8. The plot of the plasma frequency and electron density which form the electron cloud sensors. The sensitivities of 2.31 prads $^{-1} \mathrm{~mm}^{3}$ (electrons) ${ }^{-1}, \quad 2.27 \mathrm{prads}^{-1} \mathrm{~mm}^{3}$ (electrons) ${ }^{-1}, \quad 2.22 \mathrm{prads}^{-1} \mathrm{~mm}^{3}$ (electrons) ${ }^{-1}, \quad 2.38 \mathrm{prads}^{-1} \mathrm{~mm}^{3}$ (electrons) ${ }^{-1}$ are respectively obtained, where $\mathrm{p}$ is Pico $\left(10^{-12}\right)$.
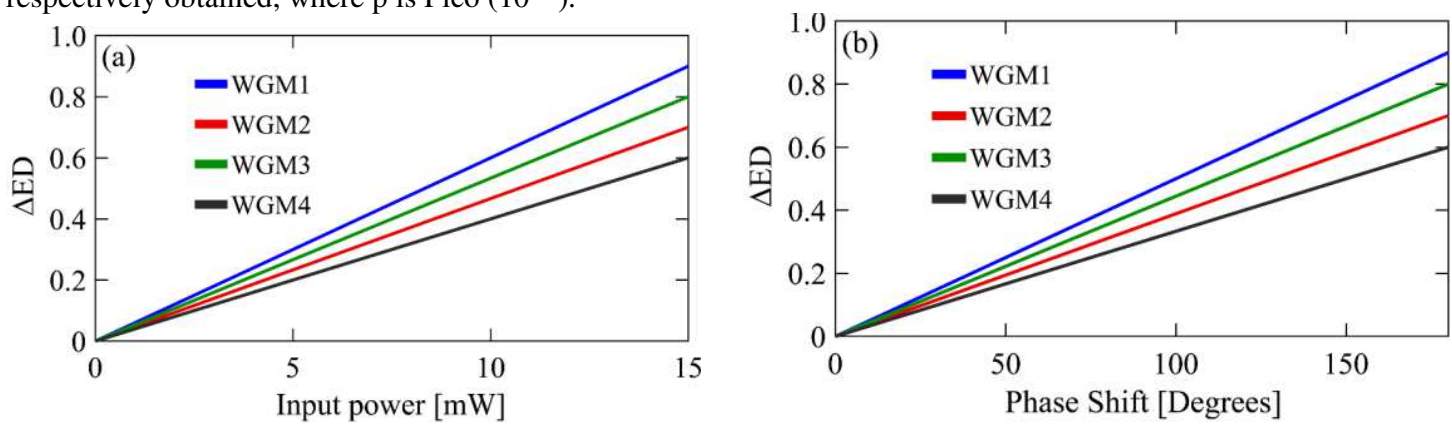

Figure 9. The plot of the (a) change in electron density (normalized electron density) and input power. The sensitivities of $0.06 \mathrm{~mW}^{-1}, 0.04 \mathrm{~mW}^{-1}, 0.05 \mathrm{~mW}^{-1}, 0.03 \mathrm{~mW}^{-1}$ are obtained respectively for WGM1-WGM4, (b) change in electron density (normalized electron density) and phase shift. The sensitivities of $0.005\left({ }^{\circ}\right)^{-1}, 0.003\left(^{\circ}\right)^{-1}, 0.004\left({ }^{\circ}\right)^{-1}, 0.002\left({ }^{\circ}\right)^{-1}$ are obtained respectively for WGM1-WGM4. The self-calibration among four-point probes can be applied.

The motivation is to design and model the quantum distributed sensors using large area MEMs sensors. The trapped electron clouds are plotted in terms of electron components (spins) density and used for distributed sensors. The new findings are the MEMs sensors and four-point probe technique, which can apply to large-area sensors using the distributed sensing probes. It has the potential of a brain-interfacing device, where selfcalibration among the four-point sensing probes can be applied. From Figure 1, the trapped electron clouds are distributed within the circuit. The polarized control is applied to the sensing probe add port. The total electron cloud phase shift of each sensing probe within the system is given by an equation (10), which is obtained by the polarized electron cloud phase shift of an equation (5). The result of each probe can be identified by the different traveling times. A polarizing beamsplitter is arranged before the detector at the Sagnac interferometer output, from which the electron cloud spin-up or spin-down components can be obtained by polarization orientation arrangement. In manipulation, when the input light power varied, the sensor sensitivity relates to electron cloud density can be obtained.

\section{Conclusion}

A Sagnac interferometer and microring integrated circuit for electron cloud sensors is proposed. When light propagates inside the Sagnac loop, it goes in both clockwise and anticlockwise directions. The microrings are embedded with silver nano-bars. The electron cloud is trapped and oscillated inside the microrings, where the WGM formation takes place, the plasmonic wave generates. Four plasmonic antennas formed at the center microrings, where the frequency wavelength spectra are employed for $\mathrm{WiFi}$ and $\mathrm{LiFi}$ sensing probes, respectively. The obtained antenna gains are $2.59 \mathrm{~dB}, 0.93 \mathrm{~B}, 1.75 \mathrm{~dB}$, and $1.16 \mathrm{~dB}$ for antenna- 1 to 4 , respectively. These four nodes behave as electron cloud sensors. Four WGM output intensities are obtained with the sensitivities of $1.35 \mu \mathrm{m}^{-2}, 0.90 \mu \mathrm{m}^{-2}, 0.97 \mu \mathrm{m}^{-2}$, and $0.81 \mu \mathrm{m}^{-2}$, respectively. Four electron cloud sensors are obtained with the sensitivities of 2.31 prads $^{-1} \mathrm{~mm}^{3}$ (electrons) ${ }^{-1}, 2.27$ prads $^{-1} \mathrm{~mm}^{3}$ (electrons) ${ }^{-1}, 2.22$ prads $^{-1} \mathrm{~mm}^{3}$ (electrons) ${ }^{-1}$, and 2.38 prads $^{-1} \mathrm{~mm}^{3}$ (electrons) $)^{-1}$, respectively. The proposed MEMs sensors can be applied to sense the physical parameters related to the electron excitation, where the changes can be detected and measured. The new findings are the MEMs sensors and four-point probe technique, which can apply to large-area sensors using the distributed sensing probes. It has the potential of a brain-interfacing device, where self-calibration among the four-point sensing probes can be applied. In application, the deep-brain signal detection related to quantum consciousness for human deep-learning investigation can be realized. 


\section{Acknowledgement:}

The authors would like to acknowledge the research facilities from Ton Duc Thang University, Vietnam.

Funding: Not applicable.

Competing Interests: The authors have declared no conflict of interest.

Availability of data and materials: Not applicable.

Code availability: Not applicable.

Authors Contributions: Aanita Garhwal: simulation, analysis, writing original draft; Arumona Edward Arumona: Matlab results improvement, review and discussion, Phichai Youplao: validation, comparing Optiwave and Matlab results, visualization, and discussion, Kanad Ray: modeling, analysis, discussion, final editing; Preecha Yupapin: conceptualization, supervision, review, editing and submission. All authors have read through the manuscript.

Ethics approval: Not applicable

Consent to Participate:

All authors are agreed to participate in this article.

Consent for Publication:

All authors are agreed to publish this article.

\section{References}

1. Musa SMA, Baharin NF, Azmi AI, Ibrahim RKR, Abdullah AS, Noor MYM, QiH (2018) Double-clad fiber Michelson interferometer for measurement of temperature and refractive index. Microwave and Optical Technology Letters 60, 4, 822-827.

2. Benleumli A, Boubekeur N, Massicotte D (2019) A highly sensitivite substrate integrated waveguide interferometer applied to humidity sensing. IEEE Microwave and Wireless Components Letters 29 1, 68-70.

3. Ruan J, Hu L, Lu H, Lu W, Zhu J, Xu H (2017) Temperature sensor employed TCF-PMF fiber structure- based Sagnac interferometer. IEEE Photonic Technology Letters 29,16, 1364-1366.

4. Liu Q, Liang X, Zhaoxia W, Lu C, Zerui Z, Jincheng Z (2020) High sensitivity photonic crystal fiber force sensor based on Sagnac interferometer for weighing. Optics and Laser Technology 123,105939.

5. Chen W, Shuqin L, Liwen W, Hui Z, Wenliang L, Shuisheng J (2011) Highly sensitive torsion sensor based on Sagnac interferometer using side-leakage photonic crystal fiber. IEEE Photonics Technology Letters 23, 21, 1639-1641.

6. Zu P, Chi CC. Yongxing J, Tianxun G, Yifan Z, Li HC, Xinyong D (2011) A temperature insensitive twist sensor by using low birefringence photonic crystal fiber based Sagnac interferometer. IEEE Photonics Technology Letters 23, 13, 920-922.

7. Gong H, Haifeng S, Sulei Z, Yongxing J, Xinyong D (2014) Curvature sensor based on hollow core photonic crystal fiber Sagnac interferometer. IEEE Sensors Journal 14, 3, 777-780.

8. Menon MV, Tong W, Li C, Xia F, Glesk I, Prucnal RP, Forrest RS (2003) All-optical wavelength conversion using a regrowth-free monolithically integrated Sagnac interferometer. IEEE Photonics Technology Letters 15, 2, 254-256.

9. Suzuki M, Takahashi T, Aoyagi S, Amemiya Y, Fukuyama M, Yokayama S (2011) A study of Mach- Zehnder Interferometer type optical modulator applicable to an accelerometer. Japanese Journal of Applied Physics, 50, 04 DG14.

10. Porzi C, Falconi F, Ansalone L, Ghelfi P, Bogoni A (2021) Fast-reconfigurable microwave photonics phase shifter using silicon microring resonators. IEEE Journal of Quantum Electronics 87, 1, 1-19.

11. Mamdouh T, Khalil D (2005), A MEMS tunable optical ring resonator filter. Optical and Quantum Electronics 37, 835853.

12. Liu T, Pagliano F, Veldhoven R-V, Pogoretskiy V, Jiao Y, Fiore A (2019) Low-voltage MEMS optical phase modulators and switches on a indium phosphide membrane on silicon. Applied Physics Letters 115, 25, 251104.

13. Garhwal A, Arumona AE, Ray K, Youplao P, Suwandee S, Yupapin P (2020) Microplasma source circuit using microring space-time distrotion control. IEEE Transactions on Plasma Science 48, 10, 3600-3605.

14. Wan S, Niu R, Ren H-L, Zou C-L, Guo G-C, Dong C-D (2018) Experimental demonstration of dissipative sensing in a self-interference microring resonator. Photonics Research 6, 7, 681-685.

15. Hasanah L, Nugroho HS, Wulandari C, Mulyanti B, Berhanuddin DD, Haron MH, Menon S, Zain ARM, Hamidah I, Khairurrijal K, Mamat R (2020) Enhanced sensitivity of microring resonator-based sensors using finite difference time domain method to detect Glucose levels for diabetes monitoring. Applied Sciences 10, 4191.

16. Ho V, W L, Chang Y, Liu Y, Zhang C, Li Y, Davidson RR, Little BE, Wang G, Chu ST (2020) Optical trapping and manipulating with a silica microring resonator in a self-locked scheme. Micromachines 11, 202.

17. Abdolvand R, Bahreyni B, Lee E-YJ, Nabki F (2016) Micromachined resonators: A review. Micromachines 7, 160. 
18. Xu Y, Hu X, Kundu S, Nag A (2019) Afsarimanesh, N.; Sapra, S.; Mukhopadhyay, C.S.; Han, T. Silicon based sensors for biomedical applications: A review. Silicon 19, 2908.

19. Chellasivalingam M, Imran H, Pandit M, Boies MA, Seshia AA (2020)Weakly coupled piezoelectric MEMS resonators for aerosol sensing. Sensors 20, 3162 .

20. Tu X, Song C, Huang T, Chen Z, Fu H (2019) State of the art and perspectives on silicon photonic switches. Micromachines, 10, 51.

21. Garhwal A, Ray K, Arumona AE, Bharti GK, Amiri IS, Yupapin P (2020) Spin-wave generation using MZI embedded plasmonic antennas for quantum communications. Optical and Quantum Electronics 52:241, 1-12.

22. Feng Z, He Y, Yan W, Yang F, Han W, Li Z (2020) Progress of waveguide ring resonator in Micro-optical gyroscopes. Photonics, 7, 96.

23. Arumona AE, Garhwal A, Youplao P, Amiri IS, Ray K, Punthawanunt S, Yupapin P (2020) Electron cloud spectroscopy using micro-ring Fabry-Perot sensor embedded gold grating. IEEE Sensors Journal 20, 18, 10564-10571.

24. Zheng SN, Zou J, Cai H, Song FJ, Chin LK, Liu PY, Lin ZP, Dwong DL, Liu AQ (2019) Microring resonator-assisted Fourier transform spectrometer with enhanced resolution and large bandwidth in single chip solution. Nature Communication, 10, 2349.

25. Yuan W, Yu C (2021) Dual demodulation of temperature and refractive index using ring core fiber based Mach-Zehnder Interferometer. Micromachines 12(3), 258.

26. Yupapin PP, Sarapat N (2013) Novel micro-scale sensors using WGMS within the modified ass-drop filter circuits. Microwave and Optical Tehcnology Letters 56, 1, 14-17.

27. Bunruangses M, Arumona AE, Youplao P, Pornsuwancharoen N, Ray K, Yupapin P (2020) Modeling of a superconducting sensor with microring- embedded gold-island space-time control. Journal of Computational Electronics $19,1678-1684$.

28. Tuniz A, Bickerton O, Diaz JF, Kasebier T, Kley B-E, Kroker S, Palomba S, Sterke M (2020) Modular nonlinear hybrid plasmonic circuit. Nature Communications 11:2413.

29. Yao J, Leuenberger D, Lee MC-M, Wu C.M. (2007) Silicon microtoroidal resonators with integrated MEMS tunable coupler. IEEEJournal of Selected topics in Quantum Electronics 13, 2, 202-208.

30. Mehdipoor M, Ghavifekr BH (2020) A novel microfluidics integrated biosensor based on a MEMS resonator. Microsystem Technologies 26, 181, 3821-3828.

31. Du H, Chau SF, Zhou G (2016) Mechanically-tunable photonic devices with on-chip integrated MEMS/NEMS actuators. Micromachines 7, 69, 1-24.

32. Uranga A, Teva J, Verd J, Lopez JL, Torres F, Abadal G, Barniol N, Esteve J, Murano-PF (2006), CMOS integrated MEMS resonator for RF applications. IEEE International Symposium on Circuits and Systems Kos, Greece, 2301-2304.

33. Youplao P, Pongwongtragull P, Mitatha S, Yupapin PP (2011) Crosstalk effects of quantum key distribution via a quantum router. Microwave and Optical Technology Letters 53, 5, 1094-1099.

34. Arumona AE, Amiri IS, Punthawanunt S, Ray K, Singh G, Bharati GK, Yupapin P (2020) 3D-quantum interferometer using silicon microring-embedded gold grating circuit. Microscopy Research and Technique 83, 10, 1217-1224.

35. Prateep P, Surasak C, Yupapin PP (2016) Analytical and simulation of a triple micro whispering gallery mode probe system for a 3D blood flow rate sensor. Applied Optics 55, 33, 9504-9513.

36. Babar S, Weaver JH (2015) Optical constants of Cu, Ag and Au revisited. Applied Optics 54, 3, 477-481.

37. Balanis CA (2005) Antenna theory analysis and design. 4th ed., Wiley, Hoboken, 1-1104. 
(a)
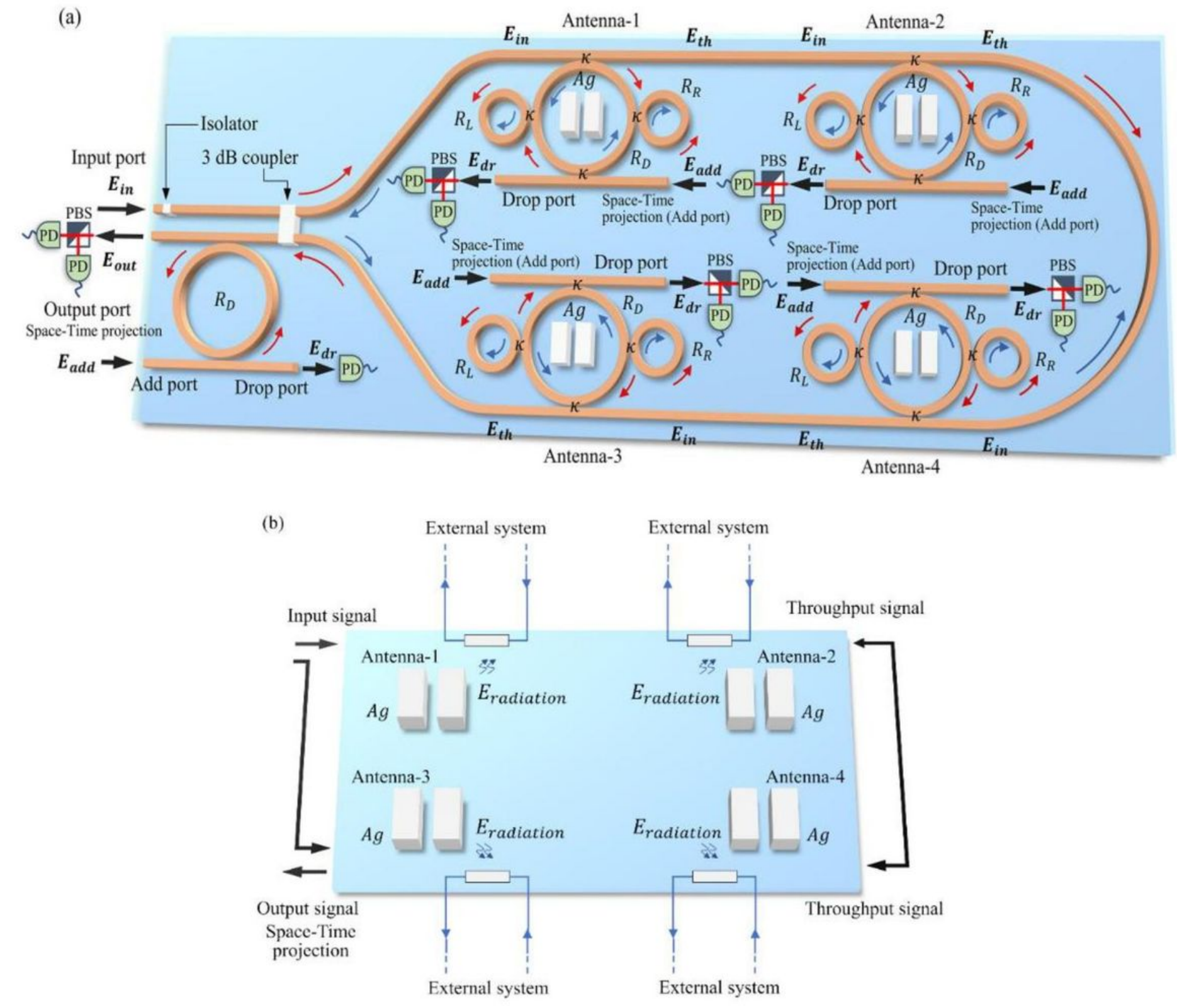

\section{Figure 1}

The device fabricated/ simulated structure of proposed work, where (a) micro-electron cloud sensors network system; Ein, Eth, Edr, E add are electric fields at input, throughput, drop and add ports, respectively. $\mathrm{K}$ is coupling constants. PBS: Polarizing beamsplitter, PD: photodetector. The polarized electron cloud components can be obtained, (b) an equivalent sensing probe circuit. The micro rings are embedded with silver (Ag) nano bars. The optical isolator is applied to project the feedback to the laser source. 

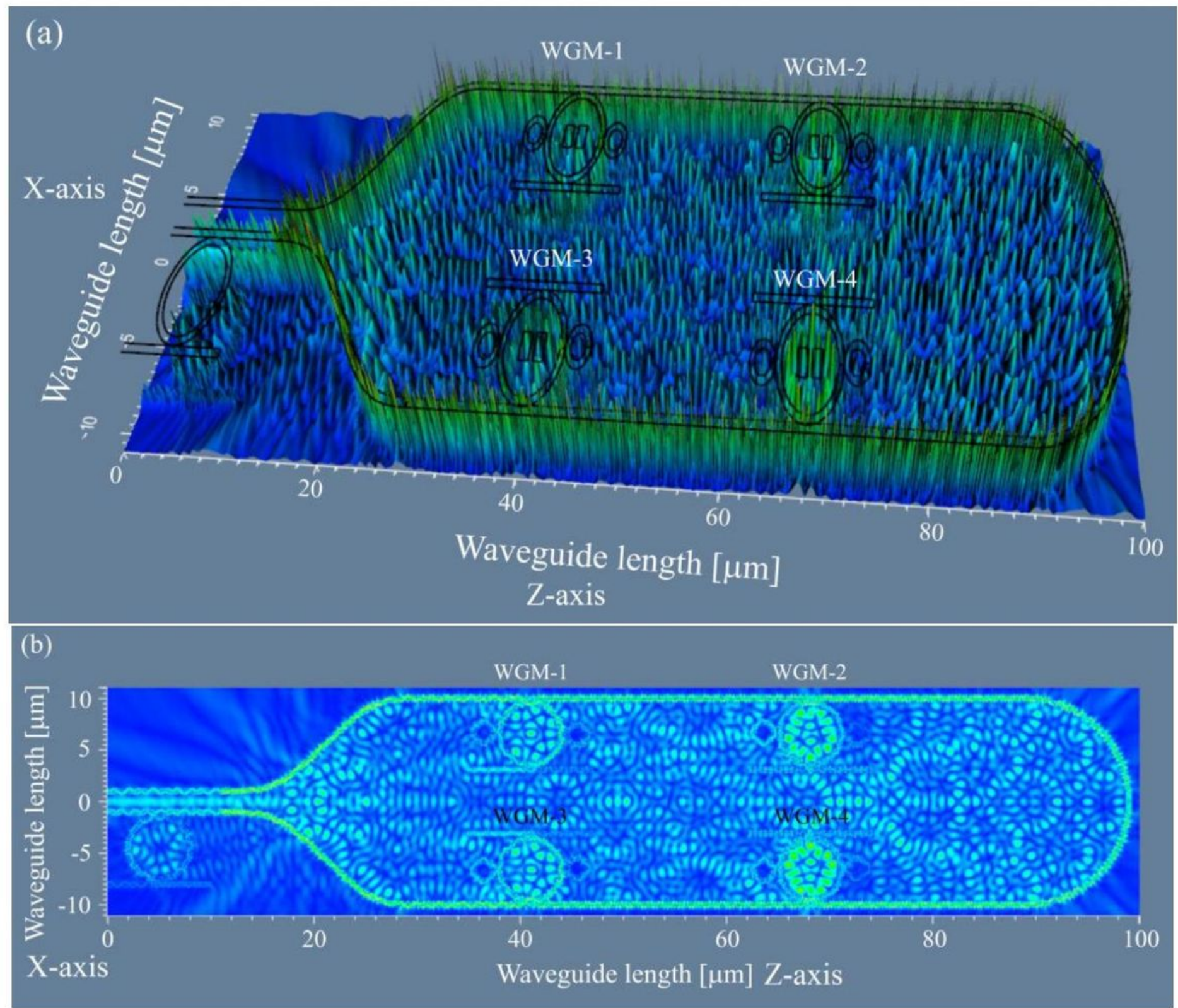

\section{Figure 2}

The Optiwave graphical results, where (a) WGMs formation; (b) plasmons propagating in the system. Input source is a polarized laser with of wavelength $1.50 \mu \mathrm{m}$. The used parameters of simulation are given in Table 1, where $\mathrm{z}$ is the propagation axis. 

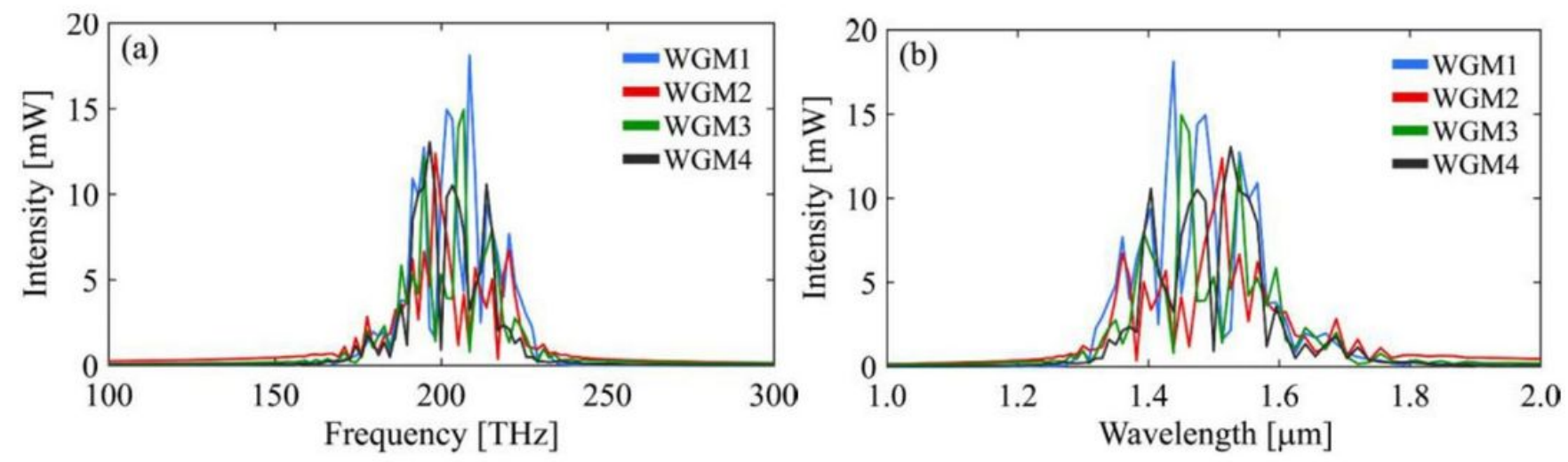

Figure 3

The plot of the input intensities and (a) frequency and (b) wavelength for all WGMs. The peak frequencies of WGM-1, WGM-2, WGM-3, and WGM-4 are 208.43THz, 198.18THz, 206.72 and, 196.47THz, respectively.

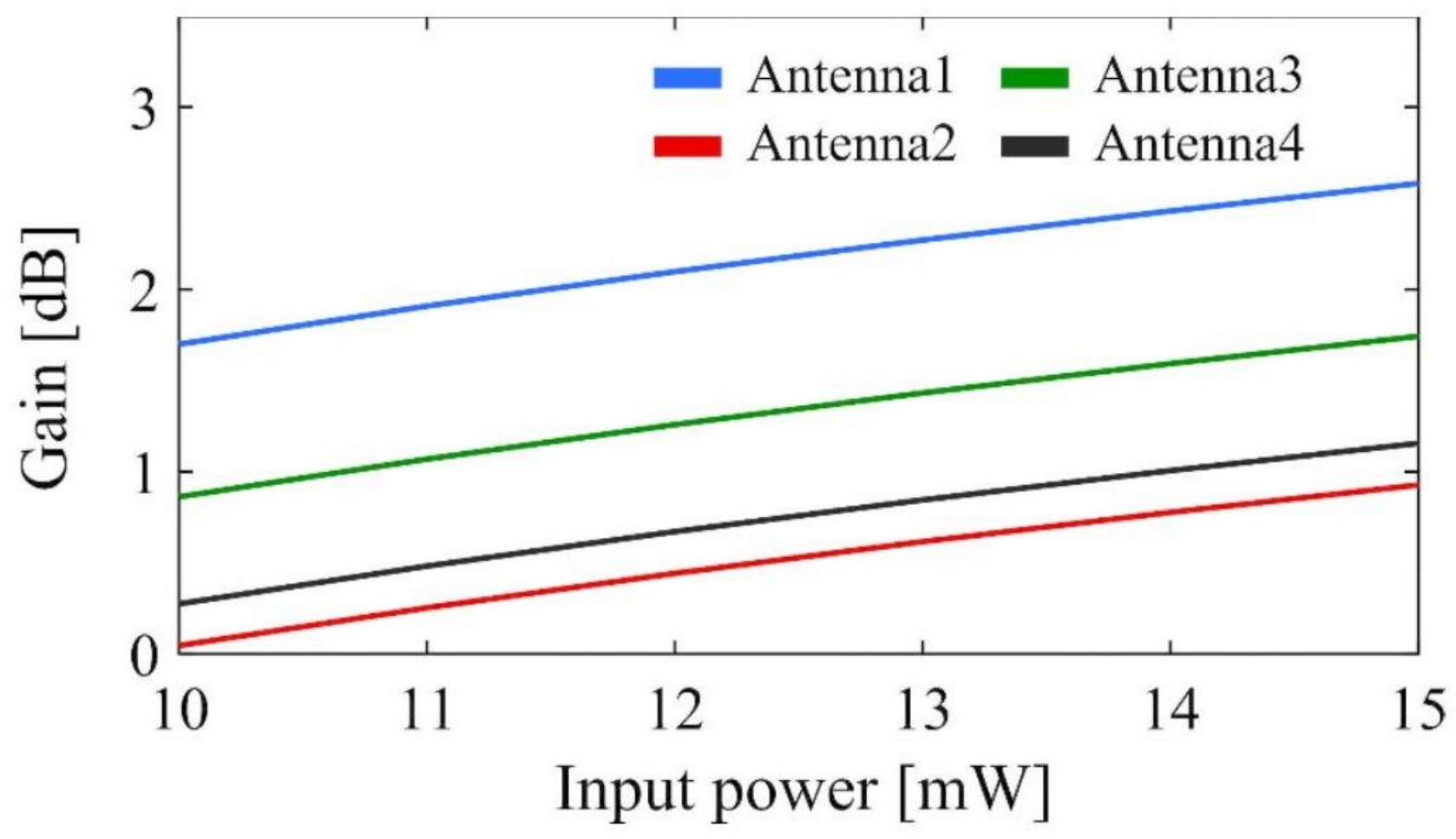

Figure 4 
The plot of antennas' gains and input power. The input power varied from $10-15 \mathrm{~mW}$. The obtained gains are $2.59 \mathrm{~dB}, 0.93 \mathrm{~dB}, 1.75 \mathrm{~dB}$, and $1.16 \mathrm{~dB}$ for antenna- 1 , antenna-2, antenna-3, and antenna-4, respectively.
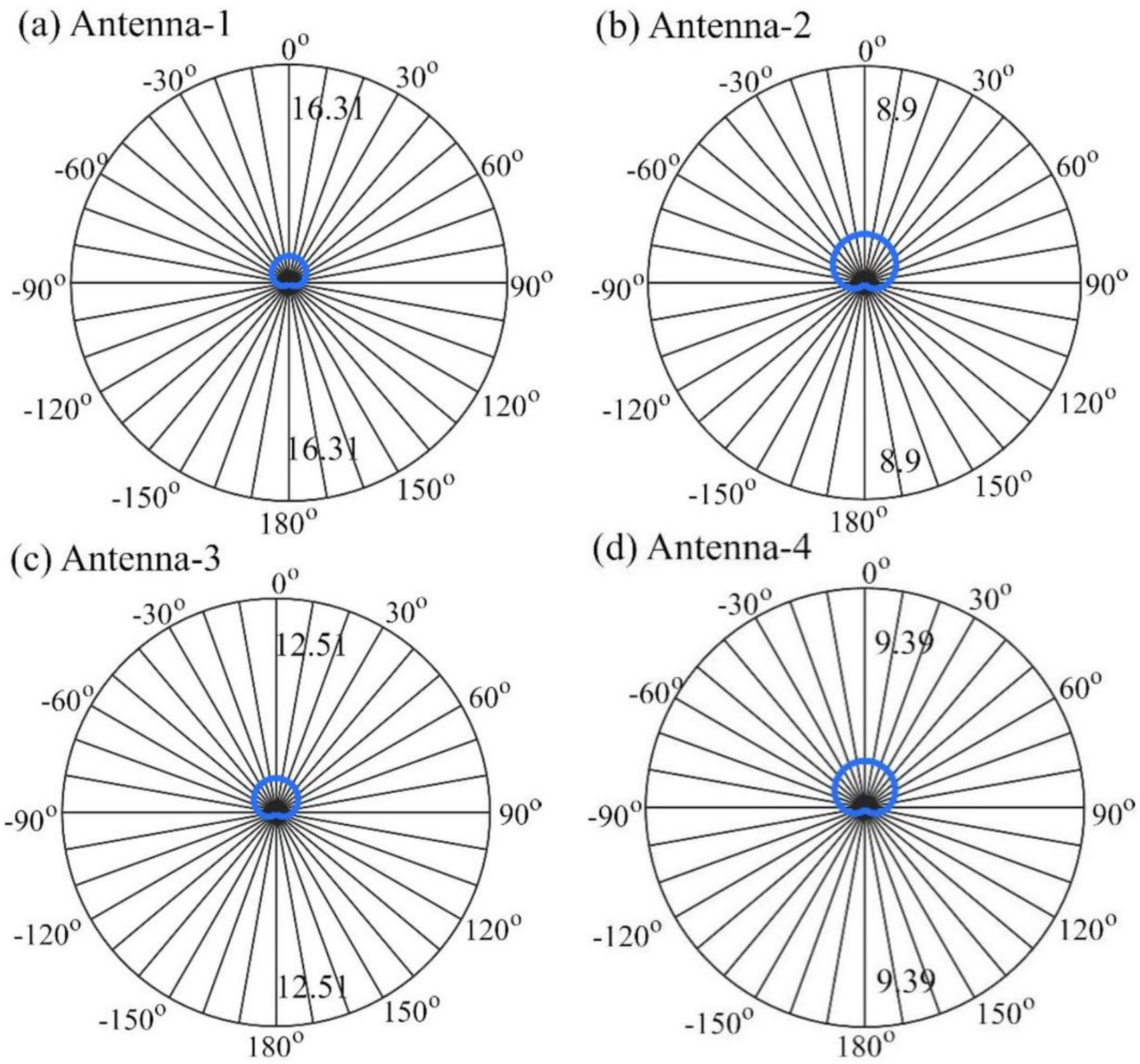

\section{Figure 5}

The plot of directivities of antennas, where the obtained directivities are 16.31, 8.9, 12.51, and 9.39 for antenna- 1 , antenna-2, antenna-3, and antenna-4, respectively. 

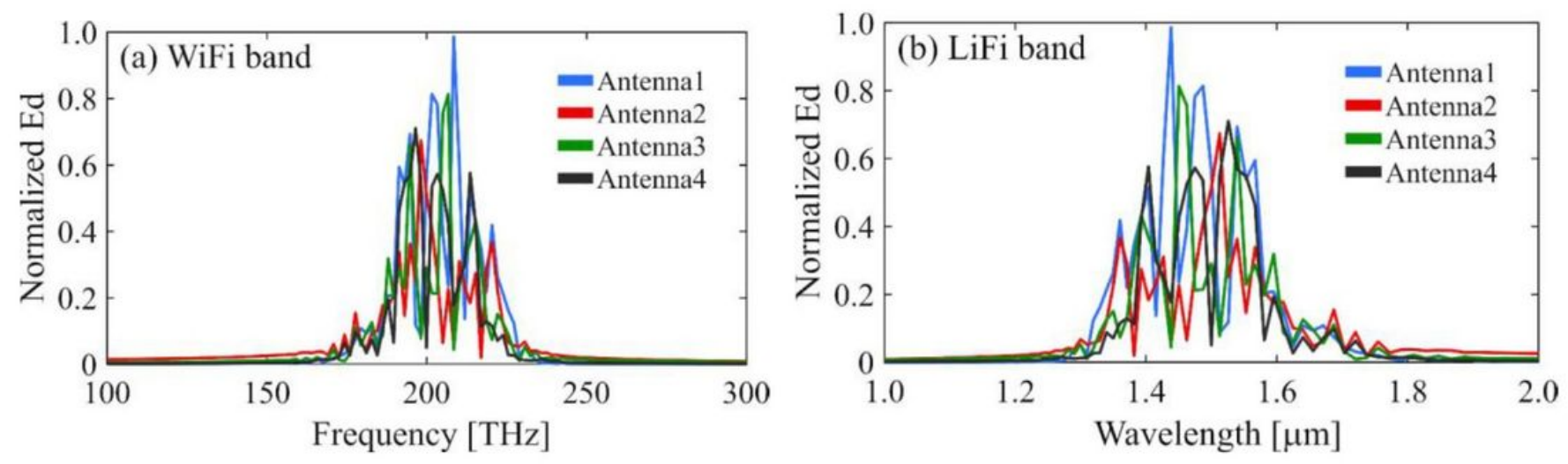

Figure 6

The plot of antenna profiles, where (a)WiFi band frequencies of antenna 1 to 4 are 208.43THz, 198.18THz, 206.72THz, and 196.47THz, respectively, (b)LiFi band wavelengths of antenna 1 to 4 are $1.43 \mu \mathrm{m}, 1.51 \mu \mathrm{m}, 1.45 \mu \mathrm{m}, 1.52 \mu \mathrm{m}$, respectively.

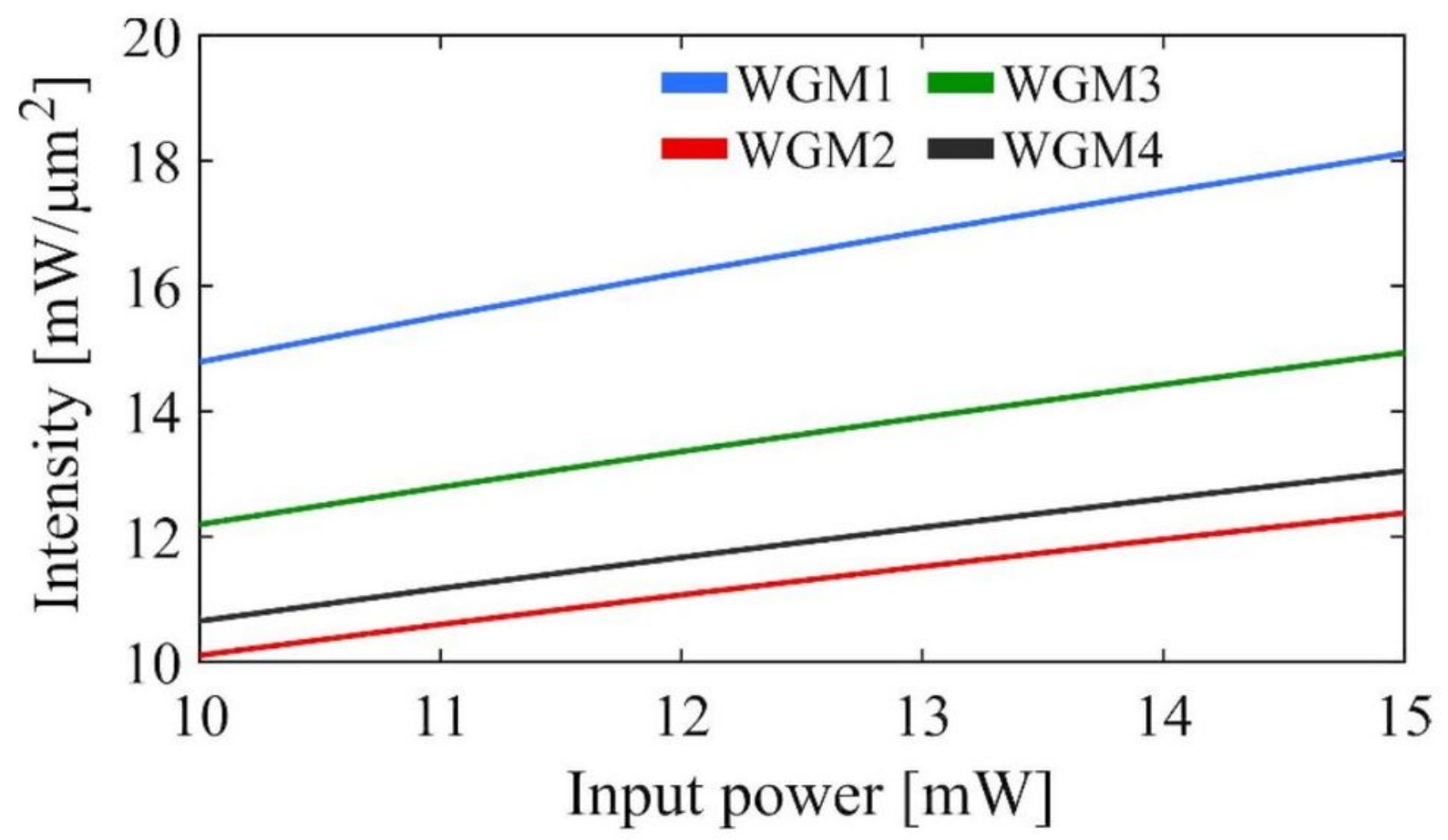

Figure 7 
The plot of the output intensities for all WGMs and input power which form the WGM sensors. The input power is varied from $10-15 \mathrm{~mW}$. The sensitivities of $1.35 \mu \mathrm{m}-2,0.90 \mu \mathrm{m}-2,0.97 \mu \mathrm{m}-2$, and $0.81 \mu \mathrm{m}-2$, are obtained, respectively.

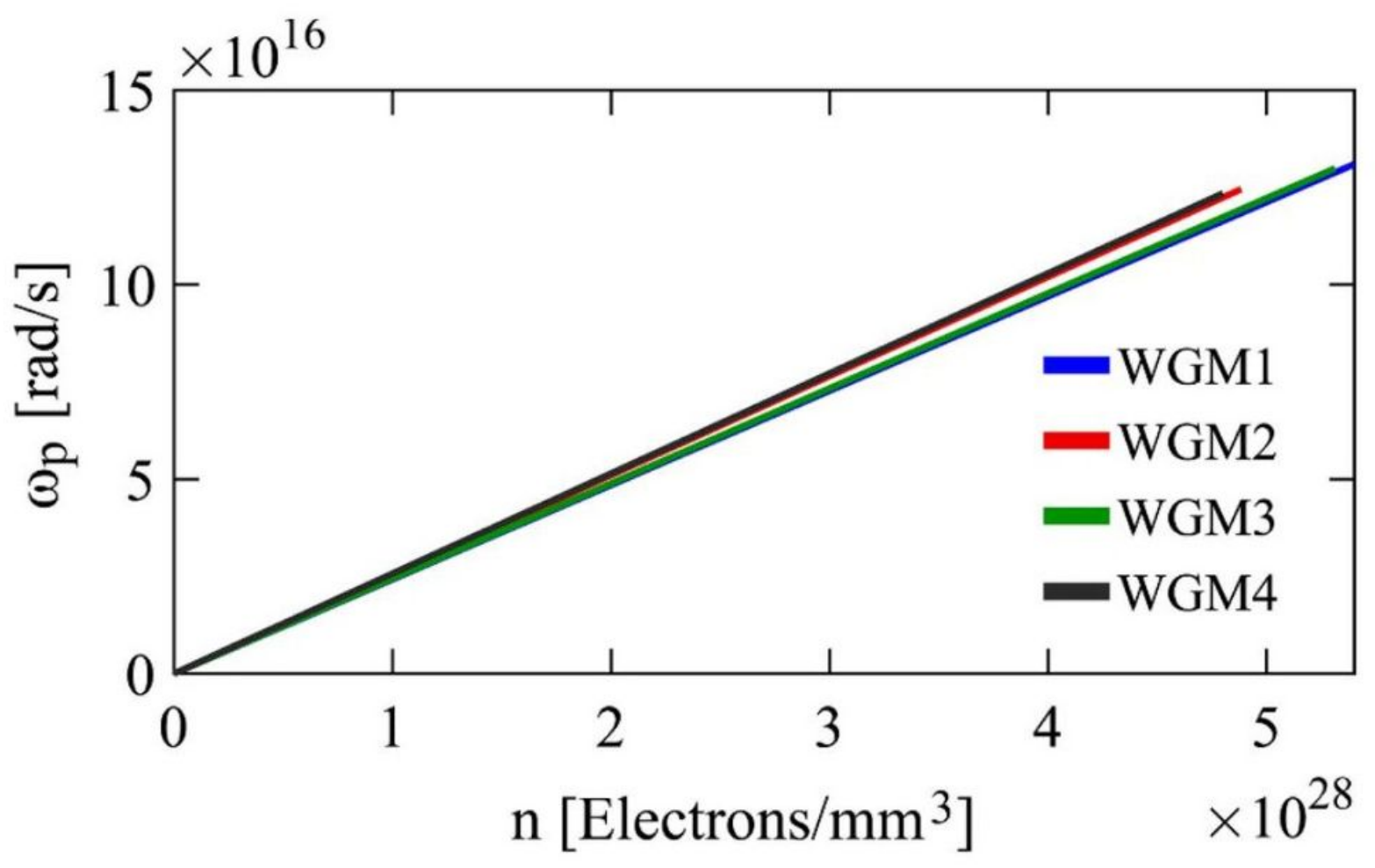

Figure 8

The plot of the plasma frequency and electron density which form the electron cloud sensors. The sensitivities of 2.31 prads- $1 \mathrm{~mm} 3$ (electrons)-1, 2.27prads- $1 \mathrm{~mm} 3$ (electrons)-1, 2.22prads$1 \mathrm{~mm} 3$ (electrons)-1, 2.38prads-1 mm3(electrons)-1 are respectively obtained, where $\mathrm{p}$ is Pico (10-12).
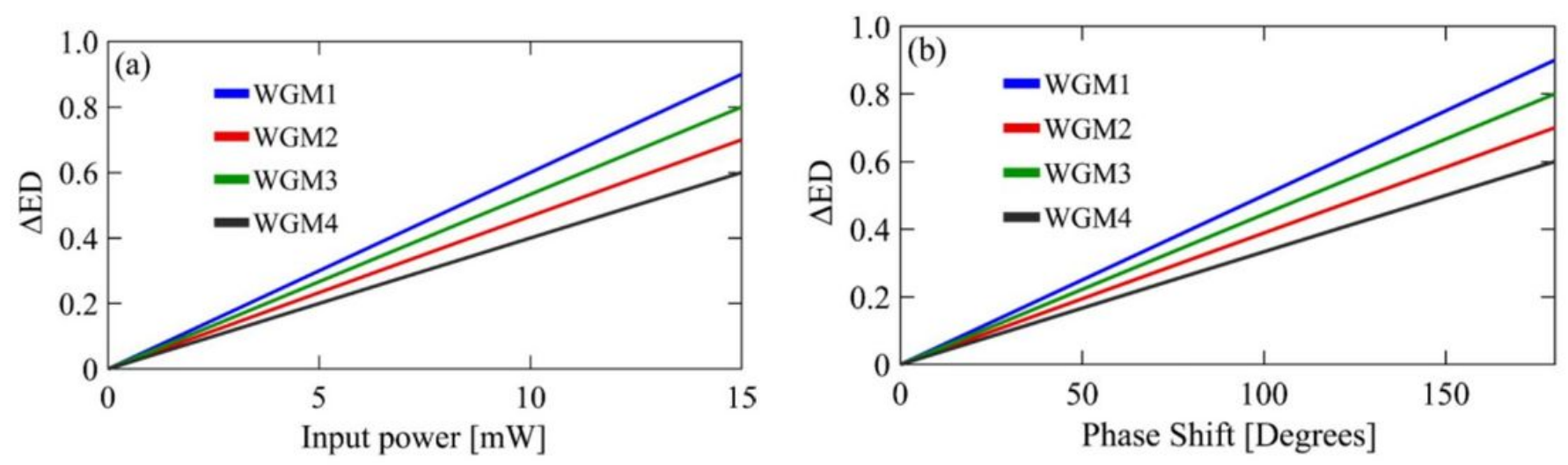


\section{Figure 9}

The plot of the (a) change in electron density (normalized electron density) and input power. The sensitivities of $0.06 \mathrm{~mW}-1,0.04 \mathrm{~mW}-1,0.05 \mathrm{~mW}-1,0.03 \mathrm{~mW}-1$ are obtained respectively for WGM1-WGM4, (b) change in electron density (normalized electron density) and phase shift. The sensitivities of 0.005(o)-1, 0.003(0)-1, 0.004(o)-1, 0.002(o)-1 are obtained respectively for WGM1-WGM4. The selfcalibration among four-point probes can be applied. 